\title{
RADIO-METEOROLOGY
}

\section{CONFERENCE IN TEXAS}

A

CONFERENCE on radio-meteorology was held in Austin at the University of Texas during November 9-12 last, sponsored by the American Meteorological Society, the Institute of Radio Engineers, the Radar Weather Conference, and the American national groups of Commission II of the International Scientific Radio Union and of the Joint Commission on Radio-Meteorology of the International Council of Scientific Unions. Some two hundred participants, widely representative of university, government and industrial scientific laboratories, attended the meetings.

The subject of radio-meteorology, which embraces several aspects both of the influence of meteorological factors on radio-wave propagation and of the use of radio techniques for studying features of the weather, has expanded greatly and increased in importance during the past few years. Work is still in progress in different parts of the world which is directed to the explanation of phenomena of which something was known twenty or more years ago ; in addition, new fields of investigation, largely stimulated by wartime experiences in the operation of centimetre-wave radar, are being intensively pursued.

\section{Tropospheric Wave Propagation}

The conference was organized into eleven sessions, and the first four of these were concerned with the effects of the troposphere on the propagation of very short radio waves. The first paper, by T. J. Carroll, presented a review of existing knowledge of tropospheric propagation to points well beyond the horizon. Experiments during recent years have shown that, at such ranges of transmission, radio field strengths at very high frequencies are much greater and more reliable than have been predicted from standard theory. Of the explanations advanced to account for this phenomenon, there was considerable discussion of two, namely: that the fields are due to scattering of incident radiation caused by turbulent fluctuations of the refractive index of the atmosphere; and that the partial internal reflexion arising from the normal negative gradient of refractive index in the atmosphere is in itself sufficient to give fields of the order of magnitude of those observed. But it would appear that the explanation in terms of scattering by turbulent eddies finds the greatest support. Although it is felt that the scattering theory needs some refinement, it is not generally considered that the partial internal reflexion hypothesis has anything to offer towards such refinement; some account must ultimately be taken of the fact that the scattering centres are not spherical, which has so far been assumed to be the case.

Scattering of radio waves from a turbulent elevated layer formed the subject of a paper by W. E. Gordon, who said that airborne radio-refractometer observa. tions in the United States indicate that such layers occur frequently. Within the layer the scale of turbulence is observed to be somewhat larger, and the intensity many times greater, than the values of these quantities observed above or below the layer. The scattered power from the layer received at certain distances may easily equal or exceed that from an atmosphere without such a layer.
Centimetre-wave refractometers are being exploited on an increasing scale in the study of the detailed refractive-index structure of the atmosphere, and these instruments have now been carried by aircraft to altitudes of $25,000 \mathrm{ft}$. Investigations of this nature were described by C. M. Crain and J. R. Gerhardt, by L. W. Cowan and by P. B. Taylor. The development of this form of refractometer as a new and sensitive instrument for the exploration of the refracting properties of the atmosphere of interest both to the meteorologist and the radio engineer, represents one of the most important steps of recent years in this field of study. Measurements of atmospheric refractive index have already been made over many coastal and interior regions of the United States for a wide range of elimatic conditions. Airborne soundings have shown the existence of intense discontinuity layers which are not nearly well enough delineated by ordinary radio-sonde ascents. Examinations of turbulent structure show scales up to hundreds of metres with fluctuations of refractive index in the free air of the order of $10^{-8}$ (1 $M$-unit)except in extremely turbulent layers where greater fluctuations are found-and decreasing as the altitude inoreases.

Considerable interest was shown at the conference in the properties of elevated layers in which the lapse-rate of refractive index with height is significantly greater than that appropriate to the standard atmosphere. Such layers, which usually occur at various heights below about $10,000 \mathrm{ft}$., play an important part in the determination of veryshort-wave propagation characteristics. B. M. Fannin described the application of ray-tracing techniques to the evaluation of radio field-strengths in the presence of these layers, and P. B. Taylor diseussed the effect of the layers on air-to-air propagation at very high frequencies in producing what has become known as the 'radio hole'. As two aircraft fly apart at a constant height above one of these abnormally refracting layers, it is frequently observed that there is a deep fade in the radio signal during communication between the aircraft. This 'radio hole' begins at a range of 50-200 miles, depending upon the heights of the aircraft and the layer, and continues out for a further 50-100 miles; beyond this the signal reappears in strength and rises, with intermittent fades, to levels well above the free-space value. Often a useful signal continues far beyond the normal radio-horizon. Some theoretical aspects of reflexion at elevated layers in very-high-frequency transmission between ground stations were outlined by F. H. Northover.

During the sessions on tropospheric wave propagation, a group of papers was presented by members of the staff of the Central Radio Propagation Laboratory of the National Bureau of Standards. Reviewing the programme of propagation research at the Bureau in the frequency band $100-1,000 \mathrm{Mc} . / \mathrm{s}$. , J. W. Herbstreit said that the programme has included studies of terrain and meteorological effects on transmission loss within and beyond the line of sight. An important series of measurements is that being carried out with transmitters located at the Cheyenne Mountain Field Station, Colorado Springs, and with receiving points situated at various dis- 
tances over the plains of Colorado, Kansas and Arkansas. B. R. Bean described the prolonged space-wave fade-outs within the radio-horizon which have been found to occur in these experiments at a frequency of $1,046 \mathrm{Mc} / \mathrm{s}$. The occurrence of these fade-outs coincides with widespread nocturnal superrefraction, as evidenced by enhanced signals beyond the line-of-sight and ground modification of the refractive index profile. A paper on the meteorological instrumentation at the Mountain Field Station was presented by M. C. Thompson and K. O. Hornberg.

Climatic maps of the monthly average refractivity gradient have been drawn up for the United States for the hours of 03.00 and 15.00 G.C.r. These maps follow a regular climatic pattern, and the refractivity gradients have been correlated with the monthly median transmission loss of all available very-highfrequency propagation paths. The usefulness of this approsch for the prediction of very-high-frequency transmission loss was discussed in a paper by $B$. $R$. Bean and Frances M. Meaney. Theoretical work at the National Bureau of Standards has sought to explain the observed propagation characteristics in terms of a modification of smooth-earth diffraction theory to include the effects of irregular terrain, climatic conditions, knife-edge diffraction and scattering in the turbulent atmosphere. It might perhaps be pointed out that much of the work of the Bureau in this field is designed to be of assistance to the Federal Communications Commission in the task of frequency allocation for various very-high-frequency and ultra-high-frequency services.

Other papers on tropospheric wave propagation were concerned with the prediction of diurnal fieldstrength variations at a frequency of $100 \mathrm{Mc}$. $\mathrm{s}$. from synoptic data (by F. R. Bellaire and W. A. Arvola), a procedure which, although not yet fully explored, appears likely to prove fruitful ; while L.J. Anderson and E. E. Gossard described attempts to deduce refractive index profiles within a surface duct over the sea from meteorological measurements at two heights only, and also the associated trapping of centimetre waves. The forecasting of propagation conditions from a knowledge of the synoptic situation also formed the subject of a paper by A. D. Hood and $L$. H. Doherty, in this case the aim being to predict the performance of a radar operating over Lake Ontario at a wave-length of $3 \mathrm{~cm}$.

An account was given by C. W. Tolbert and A. W. Straiton of experimental observations on the transmission of 8-mm. waves over optical paths of various lengths up to fifty miles in which highly directive aerials were used. The signal-level was generally found to be in agreement with the free-space value corrected for absorption due to water vapour and oxygen in the atmosphere, although there were, as expected, fluctuations produced by atmospheric inhomogeneities over the path. Steady signals with small loss due to water droplets were experienced in fog, but severe attenuation was caused by showers of rain.

\section{Thunderstorm and Tornado Atmospherics}

The fifth session of the conference was devoted to the consideration of thunderstorm and tornado atmospherics, and the general problem of thunderstorm location from the observable characteristics of atmospherics. H. L. Jones described a programme of research which has as an objective the identification and tracking of tornadoes from observations of the peculiar and abundant electrical discharges accompanying severe storms. It has been found that a line-squall, even though it appears as an extended echo on a radar screen, is composed of a number of separate storm centres each acting as a generator of atmospherics; further, as the intensity of an individual storm centre increases, the rate of arrival of atmospheries at a given receiving station increases. By observing the rate of arrival of atmospherics, and also the distribution of high-and low-frequency components, it is possible to classify storms according to their severity. The more severe storms and tornadoes are characterized by an arrival rate of 10 strokes/sec. or more, and a predominance of high-frequency components.

The recording and classification of thunderstorm atmospherics by counter techniques was discussed by M. M. Newman, J. R. Stahmann and J. R. Anderson, while E. R. Pierce and T. W. Wormell, in a communicated paper, described work at the University of Cambridge which shows that regular night-time atmospherics consist either of a series of peaked pulses fitting the concept of successive ionospheric reflexions or of $a_{0}$ smooth quasi-sinusoidal oscillation that does not obey the simple reflexion picture. Regions producing quasi-sinusoidal waveforms do not generate peaked atmospherics and vice versa, and all quasi-sinusoidal wave-forms observed at Cambridge originate from the south-west at distances exceeding $1,600 \mathrm{~km}$. It was pointed out that observations near the eastern coast or the centre of the United States would assist in establishing the cause of these curious geographical effects.

The characteristics of the lightning discharge channel are important factors in the determination of the nature of atmospherics. The channel resistivity, its surge impedance, and the propagation velocity of the discharge all involve non-linear variations which lead to interesting stepped currents. It was shown by M. M. Newman how equivalent electrical circuits could be derived and used for the calculation of the currents in discharges; the currents so obtained are in good agreement with experimental observations.

What are believed to be the first P.P.I. photographs (pictures recorded on a cathode ray tube) that include information on atmospherics were presented by D. M. Swingle. This technique permits the detailed location of electrical activity among the radar storm echoes.

\section{Cloud and Precipitation Physics}

Cloud and precipitation physics were discussed in Sessions 6-9 of the conference. In a review of this field of study, S. E. Reynolds directed attention to the fact that observations have shown that it is unnecessary to invoke the Bergeron ice-crystal mechanism to account for certain types of precipitation occurring over much of the earth's surface. The development of precipitation particles without the intermediate stage of ice is well confirmed in tropical regions as well as in the middle latitudes for both coastal and inland areas.

The general characteristics of radar echoes obtained from various forms of precipitation were surveyed by Pauline M. Austin. 'A spherical rain-drop scatters radiation which is polarized in the same direction as the incident wave. For a non-spherical particle, however, some of the scattered radiation is crosspolarized, the proportion being dependent upon the shape, orientation and composition (ice, water or 
mixture) of the scatterer. Measurements made with different polarizations, or observation of the crosspolarized component, should therefore give valuable information concerning these quantities. Such measurements are especially desirable in the case of bright-band echoes, where the values of the average echo intensity are difficult to interpret. It was suggested that future research in this field may well follow two rather different lines. The first is technical in nature, and includes improvement in the extent and accuracy of the measurements, overcoming problems such as saturation of the receiver and extraneous fluctuations, and the development of the instrumentation for the quick and easy observation of such quantities as precipitation-rate and turbulence. The second type of research is related to the interpretation of the experimental data. There are, for example, many occasions where the presence of the bright band at a relatively low altitude prevents the estimation of rainfall from echo intensity except at very short ranges. This indicates the need for an empirical relation which involves not only the echo intensity and the rate of precipitation of rain, but also other pertinent quantities such as the height of the bright band, the range, and the beam-width of the antenna. A more complete analysis of the physical processes occurring within the bright band is also needed.

There is in progress in the United States and Canada a considerable amount of work on cloud and precipitation physics, and on the deduetion from the nature of precipitation echoes of such factors as rainfall intensity, the growth and melting of snowflakes, and wind shear and turbulence. Other contributions to these topics at the conference were made by D. S. Johnson, with particular reference to rain from warm clouds in Hawaii; by P. M. Austin and $R$. Wexler on the subject of radar echo intensity at different levels in steady snow; and by K. L. S. Gunn, who presented radar evidence of a generating level for snow. In the last-named work a study of vertical radar records and upper-air data for twentytwo days of snow at Montreal has revealed that welldefined snow-trail patterns occur (on a height-range radar display) on days when the air aloft is stable. In these situations snow develops in discrete generating elements, of considerable lifetime, which exist in a layer of middle cloud. The top of this cloud is less than $200 \mathrm{ft}$. above a frontal surface on these stable days. At times when the warm air is unstable, the trail patterns are not so well defined, and the top of the cloud is farther from the frontal surface.

Further papers in the cloud physies section were those on the lowering of the bright band during heavy rain (R. Wexler and J. Honig), optical transmission through rain (D. Atlas), the deformation of large raindrops (J. E. McDonald), and the reliability of radar measurements of rainfall (F.A. Huff and J. C. Neill). D. Atlas also described some quantitative measurements at a wave-length of $1.25 \mathrm{~cm}$. on the echo intensities of fog and rain. The echoes from light rain agree well with those calculated from the existing theory; but the measured intensities with heavy rain are a few decibels lower than the theory would indicate. An account was given by $R$. K. Moore of measurements made aloft of the distribution of drop sizes in thunderstorms by means of a shadowgraph technique.

J. S. Marshall discussed the manner in which the size distributions of raindrops may vary during the process of precipitation. In calculations relating to this, it is assumed that the distributions as they originate in cumulo nimbus cloud, or at the melting level, are like those observed at ground-level, but more consistent. Subsequent developments, when the drops are falling, by raindrop coalescence, cloud accretion and evaporation modify the distributions only to a small extent, so that any changes could scarcely be distinguished within the experimental accuracy of most observations. In the case of showers, wind shear can lead to a separation of the drops according to size : the resultant error in the measurement of rate of rainfall by radar, however, should diminish greatly when an average is taken either over a period of a few minutes or over an area of a few square miles.

Observations of rain echoes using a continuouswave radar system operating at a wave-length of $8 \mathrm{~mm}$. were described by D. G. Kiely, who also commented on some peculiar super-refraction effects noticed in transmissions at the same wave-length over a one-mile sea-path. In the rain-echo experiments a comparison was made between a radar system operating with a single aerial and one with dual aerials. The results show that the intensity of echoes is much less with a dual than with a single aerial system, but that there is a well-defined distance of separation between the aerials of a dual system beyond which greater spacing leads to little decrease in echo intensity. It also appears that fluctuations of the echo signal are not very dependent upon the rate of rainfall over a fairly wide range.

\section{Operational Uses of Weather Radar}

The last two sessions of the conference were devoted to papers on the operational uses of weather radar. The radar storm-detection programme of the United States Weather Bureau was outlined by V. D. Rockney, and from this it appears that although, as M. G. H. Ligda pointed out, little direct progress has been made during recent years on the utilization of radar storm observations for weatherforecasting purposes, more rapid developments in this field may be expected in the near future.

Considerable interest was aroused by papers dealing with the nature of radar echoes obtained when tornadoes are within range of observation, for any assistance in the issuing of warnings which leads to the reduction of damage caused by tornadoes is naturally of great importance in the United States. J. C. Freeman described observations of radar echoes from storms associated with tornado situations in Texas during the spring of 1953 : these observations showed that three tornadoes were elosely linked with very large and intense cloud-echoes, and in all these cases the large echoes were in a region of observable convergence of the surface winds.

A new theory concerning physical processes in the development of tornadoes was advanced by $\mathrm{F}$. $\mathrm{O}$. Rossmann. According to this theory there is no updraught in the funnel of a tornado, as is generally assumed, but on the contrary there is a strong downdraught, caused by moist labile conditions, which is stabilized by the revolving motion of the air mass in the funnel. It was further suggested that it might be possible to destroy a tornado by causing the explosion of a missile, guided by means of weather radar, at the appropriate point in the tornado, an idea which was supported by R. H. Mayer. The new theory produced much controversy and was clearly unacceptable to many members of the conference. 
D. M. Swingle and L. Rosenberg, from a mesometeorological analysis of radar weather observations in relation to the passage of cold fronts, showed that the use of a single radar in this way can lead to a worth-while improvement of short-term (two to six hours) weather forecasts for the local region.

If $a$ criticism of the conference as a whole may be ventured, it is that too many papers (some sixty in all) were presented. It might have been more profitable if a more careful selection of papers to be read had been made, thus allowing more time for general discussion.

This article is published by permission of the Director of Physical Research, Admiralty, and the Director of Radio Research, Department of Scientific and Industrial Research.

J. A. SAXTON

\section{SIXTH INTERNATIONAL CON- GRESS OF MICROBIOLOGY, ROME}

\section{REPORTS OF SYMPOSIA}

$\mathrm{T}$

HE papers presented at four of the six symposia held at the Sixth International Congress of Microbiology, Rome, have been published as supplements to the Rendiconti dell' Istituto Superiore di Sanita*. The volume dealing with the Actinomycetes contains thirteen papers dealing with the morphology, classification and general biology of the group and will be of interest mainly to specialists. It includes three papers from S. A. Waksman's team at Rutgers University dealing with the subject from the antibiotic point of view, and one by $H$. G. Thornton and F. A. Skinner discusses the antagonism between Actinomycetes and other organisms in soil. $D$. Erikson contributes a study of mycelial variation. Views on classification are expressed by P. Negroni, A. R. Prevot, H. L. Jensen, G. Penso and E. Baldacci and his co-workers.

The volume on bacterial cytology is notable not only for its written content but also for the many excellent electron micrographs illustrating the papers. Special mention must be made of a hitherto unpublished photograph of a section of Bacillus cereus made by G. B. Chapman and J. Hillier, which illustrates Stuart Mudd's introduction, and the pictures accompanying W. van Iterson's paper on flagella. K. A. Bissett discusses the nature and importance of the cell envelope. Nuclear structures are dealt with in papers by E. Kellenberger, E. D. Delamater and R. G. E. Murray. S. Mudd presents his views on bacterial mitochondria, which are challenged by $\mathrm{A}$. Winkler in another paper.

The third symposium, on microbial metabolism, contains important papers on protein synthesis by E. F. Gale and by J. Monod and M. Cohn, and $a$ most interesting report on the study of $E$. coli metabolism from a genetic point of view by B. D. Davis.

It is a little unexpected not to find any discussion of protein metabolism included among the papers on interaction of viruses and cells, and most disappointing to find no illustrations of $R$. W. $G$. Wyckoff's views on electron microscope evidence of

- VIto Congresso Internazionale di Microbiologia. Actinomycetales, Morfologia Biologia e Sistematica; pp. 221 ; $20 \mathrm{~s}$., or 1,600 lire Citologia Batterica ; pp. $181+46$ plates ; $25 s$., or 2,000 lire. Metabolismo Microbico: pp. $143+1$ plate; $12 s$. $6 t$., or 1,000 lire. Rapport tra Virus e Celiula Ospite; pp. $110+32$ plates; $15 s$., or 1,300 lire. (Roma: Fondazione Emanuele Paterno. Oxford: Blackwell Scientific Publications, Itd., 1953.) virus proliferation. P. Lepine's paper is, however, very well illustrated with electron micrographs of ultra-thin sections of virus-infected cells, although perhaps not all virologists will agree with his interpretation of them. More controversial is G. Penso's postulated life-cycle of a mycobacteriophage. $R$. Dulbecco's account of his studies of animal viruses in tissue culture by his phage technique will be read with interest by all virologists, as will P. von Magnus's paper on incomplete forms of influenza virus. Plant: viruses are discussed by F. C. Bawden, N. W. Pirie, and K. M. Smith and N. Xeros, while J. G. Carr contributes a short outline of the problem of virus reproduction in relation to cancer.

\section{NATIONAL SCIENCE FOUNDATION}

\section{REPORT FOR THE YEAR 1952-53}

TN the report of the United States National Science Foundation for the year ended June 30, 1953*, details are given of the support that the Foundation is continuing for three general long-range surveys of fields of science which are plannod to require up to three years to complete. The survey of physiological science is being conducted by the American Physiological Society, and the final report is expected in the autumn of 1954. That of the development and status of psychology is being conducted by the American Psychological Association and comprises two major parts : an evaluation of the status of psychological knowledge, with special reference to general scientific methodology, development of theory, and dependence upon empirical laws; and an analysis of occupations in psychology, including the supply, demand and utilization of scientific manpower in the various branches of the seience. The survey of applied mathematics is being conducted under the direction of the National Research Council Committee on Training and Research in Applied Mathematies in co-operation with the Defense Department.

Jointly with the universities, scientific societies and other government agencies in the United States, the Foundation sponsored eight conferences during the year, covering astrophysies, photosynthesis, the abundance and distribution of elements, highenergy physics, fibre bundles and differential geometry, methods of determination of steroids in blood and urine, specificity in development, and Lie groups and $\mathrm{Lie}$ algebras. Other conferences, symposia or meetings sponsored by the Foundation dealt with physics research in colleges, education in physiological science and the production and use of technical reports. Responsibility for maintaining a register of scientific and technical personnel in the United States was transferred from the Office of Education to the Foundation on January 1, 1953, and with financial assistance from the Foundation some ten to twelve scientific societies are setting up comprehensive registers which by June this year are expected to cover essential information on about $a$ hundred thousand scientific workers and engineers. Registers for all main fields of science should be established by June 1955, and meanwhile information already collected is being analysed and reports are being prepared on specific scientific fields. The present report gives

* The Third Annual Report of the National Sclence Foundation. Year ending June 30,1953 . Pp. vii +110. (Washington, D.C.: Gov. Printing Office, 1953.) 40 cents. 